\title{
BMJ Open Cost-benefit analysis of surveillance for surgical site infection following caesarean section
}

\author{
Catherine Wloch (10 , ${ }^{1}$ Albert Jan Van Hoek, ${ }^{2}$ Nathan Green, ${ }^{3}$ Joanna Conneely, ${ }^{1}$ \\ Pauline Harrington, ${ }^{1}$ Elizabeth Sheridan, ${ }^{1}$ Jennie Wilson, ${ }^{4}$ Theresa Lamagni ${ }^{1}$
}

To cite: Wloch C, Van Hoek AJ, Green N, et al. Cost-benefit analysis of surveillance for surgical site infection following caesarean section. BMJ Open 2020;10:e036919. doi:10.1136/ bmjopen-2020-036919

- Prepublication history and additional material for this paper are available online. To view these files, please visit the journal online (http://dx.doi org/10.1136/bmjopen-2020036919).

Received 10 January 2020 Revised 05 May 2020 Accepted 29 May 2020

Check for updates

(C) Author(s) (or their employer(s)) 2020. Re-use permitted under CC BY-NC. No commercial re-use. See rights and permissions. Published by BMJ.

${ }^{1}$ Healthcare Associated Infection and Antimicrobial Resistance,

Public Health England, London, UK

${ }^{2}$ Immunisation, Hepatitis, and Blood Safety, Public Health

England, London, UK

${ }^{3}$ Department of Infectious

Disease Epidemiology, Imperial

College London, London, UK

${ }^{4}$ Richard Wells Research Centre, University of West London, London, UK

Correspondence to Dr Catherine Wloch; catherine.wloch@phe.gov.uk

\section{ABSTRACT}

Objective To estimate the economic burden to the health service of surgical site infection following caesarean section and to identify potential savings achievable through implementation of a surveillance programme. Design Economic model to evaluate the costs and benefits of surveillance from community and hospital healthcare providers' perspective.

Setting England.

Participants Women undergoing caesarean section in National Health Service hospitals.

Main outcome measure Costs attributable to treatment and management of surgical site infection following caesarean section.

Results The costs (2010) for a hospital carrying out 800 caesarean sections a year based on infection risk of 9.6\% were estimated at $£ 18914$ (95\% Cl 11521 to 29 499) with $28 \%$ accounted for by community care ( $\$ 5370$ ). With inflation to 2019 prices, this equates to an estimated cost of $£ 5.0 \mathrm{~m}$ for all caesarean sections performed annually in England 2018-2019, approximately £1866 and $£ 93$ per infection managed in hospital and community, respectively. The cost of surveillance for a hospital for one calendar quarter was estimated as $£ 3747$ (2010 costs). Modelling a decrease in risk of infection of $30 \%, 20 \%$ or $10 \%$ between successive surveillance periods indicated that a variable intermittent surveillance strategy achieved higher or similar net savings than continuous surveillance. Breakeven was reached sooner with the variable surveillance strategy than continuous surveillance when the baseline risk of infection was $10 \%$ or $15 \%$ and smaller loses with a baseline risk of $5 \%$.

Conclusion Surveillance of surgical site infections after caesarean section with feedback of data to surgical teams offers a potentially effective means to reduce infection risk, improve patient experience and save money for the health service.

\section{INTRODUCTION}

Caesarean section delivery rates have risen in recent years in many Organisation for Economic Co-operation and Development (OECD) countries and ranged from 15.5\% of deliveries in Finland to $53.1 \%$ in Turkey in 2015. ${ }^{1}$ In England, caesarean section rates have risen from $9 \%$ of deliveries in 1980 to $30 \%$ in $2018-2019 .^{2}$

\section{Strengths and limitations of this study}

- The model estimated both community $(28 \%)$ and hospital costs $(72 \%)$, providing a more representative estimate of overall economic burden to the health service.

- Time-matching of patients with and without infection according to length of postoperative stay provided a more accurate assessment of excess bed-days attributable to surgical site infection (2.6 days) than the average excess length of stay comparison (median difference 5 days) by disentangling the impact of prolonged length of stay on increased chance of detecting an infection.

- Through capture and assessment of the costs and impact of surveillance, our model demonstrated the potential for savings through reductions in the incidence of surgical site infections.

- Costs were obtained from National Health Service National Schedule Reference Costs and other sources rather than observed expenditure and assumptions made about the number of extra midwife and general practitioner appointments resulting from infection.

- The study was based on healthcare utilisation and did not assess direct and indirect costs borne by the patients or their carers.

Surgical site infection is a common and potentially serious complication of caesarean section with risk of infection of $9 \%-11 \%$ reported previously in the UK. ${ }^{34}$ The majority of postcaesarean surgical site infections are superficial infections of the skin and subcutaneous tissue which can be managed by the community midwife and general practitioner. However, in the UK, $10 \%-13 \%$ are more serious deep infections of the muscle and fascial layer or organ/space infections (endometritis and reproductive tract infections) ${ }^{4-6}$ which may require readmission to hospital. As well as causing anxiety and pain for the patient, these infections result in costs to the health service both in terms of excess length of hospital stay and for treatment of 
the infections in the community. In very rare instances, a surgical site infection following caesarean section can have fatal consequences. ${ }^{7}$

The use of surveillance to measure the risk of surgical site infection and feedback of results to surgeons has been shown to be effective in reducing the risk of infection. ${ }^{8-10}$ However, surveillance of surgical site infection is resource intensive and studies to assess its cost-benefit have not been conducted. The Surgical Site Infection Surveillance Service at Public Health England provides national coordination for surgical site infection surveillance for hospitals in England. In 2009, Public Health England conducted a multicentre study of surgical site infection following caesarean section to test the feasibility of postdischarge detection methods and establish a national benchmark for infection risk. ${ }^{6}$ Based on the findings from the study, we undertook a further assessment of the economic burden of infection and the potential savings achievable through establishing surveillance as a means to stimulate a review of clinical practices and direct infection prevention measures.

\section{METHODS}

A cost-benefit model was constructed to estimate the costs to the health service of managing surgical site infection post caesarean section both in hospital and in the community.

\section{Cohort study}

The estimated risk of infection was based on data captured during a multicentre cohort study which followed a protocol with standard case finding methods and definitions of infection. ${ }^{6}$ Of the 4107 women followed up after caesarean section across the 14 National Health Service (NHS) centres participating in the 2009 study, 9.6\% (394) developed a surgical site infection meeting the study case definitions. Overall, $11.7 \%$ (46) of infections were organ/space (endometritis and female genital tract infections) or deep incisional infections and the remaining $88.3 \%$ were superficial incisional infections. In the cohort study, surgical site infections were detected during the initial inpatient hospital admission in which the caesarean section was performed, at readmission to hospital, in the community by midwives visiting women in their own home or via a patient questionnaire at 30 days after the operation. According to the study protocol, if an infection was detected via more than one method, a hierarchical approach was used to assign detection method such that if a patient reported (community treated) infection was also identified by the community midwife or other outpatient visit, then the surgical site infection was reported as detection by midwife or other hospital healthcare professional, respectively. Similarly, if the patient was readmitted, then detection was recorded as 'at readmission' rather than patient reported or detected by midwife/other healthcare professional.
Standard case definitions, based on clinical and laboratory findings, were used to identify surgical site infection that occurred up to 30 days after the operation. ${ }^{611}$ Table 1 shows the parameters taken from the cohort study for use in the model.

Seven of the participating hospitals repeated the surveillance for a further 3-month period and the risk of infection was compared between these two periods. The seven hospitals who repeated the surveillance for a second period carried out a total of 1212 operations with 131 infections in the first period (10.8\% risk) and 1235 operations with 89 infections ( $7.2 \%$ risk) in the second period. A slight but non-significant increase in infection risk was observed for two of the seven hospitals, whereas five hospitals experienced a decrease in infection risk, three of which were significant (figure 1). The mean reduction in infection risk between the two periods across all hospitals was $-31.2 \%$ (range from $-73.3 \%$ to $19.5 \%$ ).

\section{Hospital treatment costs}

Costs were modelled on a hospital undertaking a 3-month period of surveillance and conducting 800 caesarean sections per year (the approximate average number of operations for hospitals participating in the multicentre study).

The length of the initial hospital stay during which the caesarean section was performed was derived from data captured during the study. Rather than a simple comparison of length of stay for women with and without a surgical site infection, a case-control paired matching approach was used to estimate excess length of stay for patients with an infection diagnosed during the inpatient stay. All controls must have had a postoperative length of stay at least as long as the infection free period of stay of the paired case. The total postoperative length of stay of a patient with surgical site infection (case) and total length of stay of matched patients without infection (controls) were compared. The mean average of paired differences between cases and controls was calculated. Under the assumption that the exposure to infection is from the time of surgery onwards, then the time in hospital before caesarean section is assumed not to put the patients at additional risk of surgical site infection. As well as matching controls to the infection free period

Table 1 Parameters for surgical site infection (SSI) risk used in the model

\begin{tabular}{ll}
\hline Detection method & $\begin{array}{l}\text { Infection } \\
\text { risk }\end{array}$ \\
\hline All methods combined & $9.59 \%$ \\
\hline Inpatient detected & $0.51 \%$ \\
$\begin{array}{l}\text { Inpatient detected SSI subsequently } \\
\text { readmitted }\end{array}$ & $0.05 \%$ \\
Readmission detected & $0.56 \%$ \\
Community midwife detected & $5.31 \%$ \\
\hline Self-reported by patient & $3.21 \%$ \\
\hline
\end{tabular}




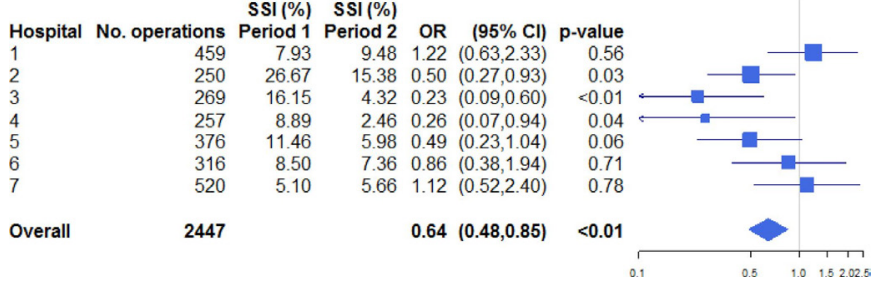

Figure 1 Change in surgical site infection (SSI) risk between consecutive 3-month surveillance periods for seven hospitals during the multicentre caesarean section study.

of the case, we selected controls by identifying patients matched on confounders to account for varying length of stay (age, antimicrobial prophylaxis, American Society of Anesthesiologists physical status score, body mass index (BMI) category, blood loss, diabetes, duration of active labour, duration of operation, urgency of risk category and wound class).

Case records of patients identified from the cohort study as having been readmitted for a surgical site infection were linked to NHS Digital Hospital Episode Statistics (HES) Admitted Patient Care Records to derive information on length of readmission stay and diagnostic reason for readmission. This enabled additional costs due to readmission to be calculated for: (1) the patients from the cohort study who had an infection detected during the inpatient period who were also readmitted to hospital for further treatment and (2) the patients from the cohort study whose infection was initially diagnosed at readmission.

The average cost of excess bed days and readmissions was identified from codes in Healthcare Resource Group data (standard groupings of clinically similar treatments which use common levels of healthcare resource listed within HES data) assigned to each patient hospital spell and linked to the National Schedule Reference Costs (the average unit cost to the NHS of providing a defined service, 2010). ${ }^{12}$

\section{Community treatment costs}

Community costs of treating and managing surgical site infection were estimated based on the assumption of one extra midwife visit, one general practitioner visit and one course of antibiotics for each surgical site infection detected by a midwife. For patient reported infections, this was assumed to be one general practitioner visit and one course of antibiotics. The cost of a community midwife postnatal visit was identified from National Schedule Reference Costs and a general practitioner visit from Unit Costs of Health and Social Care (Personal Social Services Research Unit). Antibiotic costs were obtained from the NHS Drugs Tariff. ${ }^{13}$

The proportion of patients in the study with community reported surgical site infection accompanied by positive microbiology results was employed to derive model parameters for microbiological testing. Positive microbiology results were recorded for $43 \%$ of the community midwife detected surgical site infections and $30 \%$ of patient reported infections in the cohort study. Microbiology costs were obtained by personal communication with consultant microbiologists from two NHS Trusts.

\section{Hospital surveillance costs}

Information on the staff time required to conduct a 3-month period of surveillance and administer patient questionnaires was provided by three hospitals who participated in the multicentre study. Expenses for other resources (stationery, telephone calls, stamps) needed to carry out surveillance were also recorded. This information was used to determine the average cost of surveillance (including gross salary costs) for a hospital conducting 800 caesarean sections per year.

\section{Cost-benefit analysis}

The uncertainty around the overall costs was calculated using the appropriate binomial distributions for the number of infections detected based on the proportions in the sample from the study and the reference prices. The $95 \%$ CI was obtained by running 10000 simulations in @Risk V.5.0 (risk analysis software) using Excel 2007. For the length of stay, a non-parametric approach was used for matching patients with a jack-knife error estimate, and a normal approximation was then used for the SE on the expected length of stay which was assumed to be approximately normal.

The cost-benefit model compared the total 2019 costs to the healthcare system of a scenario with and without surveillance in place (healthcare provider's perspective). The costs identified for surgical site infection following caesarean section were used to model the balance of surveillance costs versus savings over a 5 -year period (with discounting of costs at $3.5 \%$ to reflect value over the time of the analysis $)^{14}$ using Microsoft Excel. Different surveillance strategies were modelled, together with three baseline infection risks and three potential average reductions in risk of infection between each surveillance period.

The three average rates of reduction in infection risk were selected for the model given the reductions in caesarean section surgical site infection achieved during our cohort study $(31 \%)$, also seen in other European single site studies $(70 \%-80 \%$ between interventions) ${ }^{15} 16$ and observed across European surveillance networks (eg, approximately 33\% over 4 years for UK, except England). ${ }^{17}$

A range of scenarios were tested as follows:

A. baseline infection risk of $5 \%, 10 \%$ or $15 \%$.

B. Surveillance strategies of

a. One 3-month surveillance quarter a year.

b. Two 3-month surveillance quarters a year.

c. Continuous surveillance (in 3-month periods).

C. Average reductions of $10 \%, 20 \%$ or $30 \%$ in infection risk during each surveillance period.

When calculating reductions in surgical site infection risk, the model reflected a constant reduction rate over the 5-year period of study whereby the risk for each surveillance period was iteratively calculated from the 
surgical site infection risk of the previous surveillance period. A fourth surveillance strategy with a variable programme was also modelled: continuous surveillance for hospitals with a surgical site infection risk over $10 \%$, two surveillance quarters a year for surgical site infection risk between $5 \%$ and $10 \%$ and one surveillance period a year for surgical site infection risk $<5 \%$.

The simulations assumed that average reductions in risk of disease were achieved through infection control measures taken during each surveillance period and sustained between surveillance periods. The calculations also assumed that an irreducible minimum infection risk of $3 \%$ could be reached at which point no further reductions in risk of infection would be included in the model and surveillance would be reduced to one quarter per year.

\section{Patient and public involvement}

Patients or the public were not involved in the design, conduct, reporting or dissemination of our research.

This study falls within the remit of Public Health England to use patient data without explicit consent under Regulation 3 of the Health Service (Control of Patient Information) Regulations 2002 for surveillance and control of public health hazards explicitly including infectious disease.

\section{RESULTS}

\section{Treatment costs}

The estimated 2010 costs to hospital and community of surgical site infection following caesarean section at a model hospital conducting 800 caesarean sections per year are shown in table 2. For the initial hospital stay (during which the caesarean section was performed), the difference in median length of stay for the 21 patients with an infection detected during that inpatient stay, compared with those without an infection, was 5 days. Using an alternative case-control paired matching approach to account for time at risk and differences in factors other than the surgical site infection which may have increased length of stay (such as patient comorbidity), the number of excess days due to surgical site infection detected during the initial inpatient stay was calculated as 2.60 days (SE 0.082).

Costs associated with (1) two patients subsequently readmitted to hospital for further treatment of infections detected during the initial inpatient stay and (2) for readmission of 23 patients for surgical site infection were derived from Healthcare Resource Group data. The most commonly identified codes associated with the readmission spell for infection of the patients in the cohort study were: 'NZ05 Antenatal and Post-natal investigation (0 days)', 'NZ08 Antenatal and Post-natal investigation (1 day or more)'. The cost to community healthcare of microbiological testing was estimated from the mean microbiology cost of $£ 13.74$ reported by the two NHS hospitals (including pay and consumables), together with the proportions of positive microbiology results recorded in the cohort study for community midwife detected and patient-reported infections.

The estimated hospital costs resulting from a $9.6 \%$ infection risk at a model hospital conducting 800 caesarean sections a year were estimated to be $£ 13544$ with community costs estimated at $£ 5370$, an overall cost of $£ 18914$. Uncertainty calculations (95\% CI) indicated a minimum of $£ 11521$ and maximum £29 499 with the most influential parameters being infections detected on readmission, inpatient detected infections and incidence of readmission of the patients whose surgical site infection was already detected as inpatients. The two main drivers of the uncertainty in the overall outcome were the incidence of readmission and the uncertainty around the excess length of stay.

Costs were inflated to 2019 prices (table 2) using the OECD Consumer Prices Index for the United Kingdom (total less food, less energy). ${ }^{18}$ This resulted in hospital costs of $£ 16047$, community costs of $£ 6363$ and total cost of $£ 22409$. If the $9.6 \%$ infection risk identified in our cohort study was applied to the 179475 caesarean sections performed annually in England (2018-2019), this would be equivalent to 17212 infections resulting in an estimated cost of $£ 5.0$ million. The approximate cost per infection treated in hospital during inpatient or readmission stay was $£ 1866$ and was $£ 93$ for infections managed in the community by community midwives or general practitioners after discharge.

\section{Surveillance costs}

Information provided by participating hospitals indicated that a surveillance nurse would require time equivalent to 2 days a week for surveillance of 200 patients undergoing caesarean section for one quarter. The estimated cost for one quarter of surveillance at the model hospital carrying out 800 caesarean sections a year was calculated at $£ 3747$ including administrative costs (2010 prices) and £4439 when inflated to 2019 costs (table 3).

\section{Modelling cost savings from surveillance}

As might be expected, the model simulations estimating the balance of surveillance expenditure versus savings covering a period of 5 years indicated that surgical site infection risk reduced more quickly for the continuous surveillance strategy than for either one or two quarters a year surveillance where the same baseline infection risk and reductions in risk of infection were applied (figures 2-4).

Where the hospital baseline infection risk was $10 \%$, similar to the mean surgical site infection risk in the cohort study, savings over the period of simulation were greater than the costs of surveillance for all the surveillance strategies where reductions of $20 \%$ or $30 \%$ in the risk of infection were achieved. Breakeven was achieved by the end of year 2 (or sooner) where reductions of $30 \%$ between successive surveillance periods were applied and by the end of year 3 (or sooner) for reductions of $20 \%$ 
Table 2 Estimated annual hospital and community costs to the National Health Service arising due to surgical site infection following caesarean section for a model hospital conducting 800 caesarean sections per year

\begin{tabular}{|c|c|c|c|c|c|c|c|c|c|}
\hline Treatment stage & & Item & Estimate & $95 \% \mathrm{Cl}$ & $\begin{array}{l}\text { Hospital } \\
\text { costs (£) }\end{array}$ & $\begin{array}{l}\text { Community } \\
\text { costs (£) }\end{array}$ & $\begin{array}{l}\text { Total costs } \\
(£)\end{array}$ & $95 \% \mathrm{Cl}$ & $\begin{array}{l}\text { inflated } \\
\text { costs* }\end{array}$ \\
\hline \multirow{4}{*}{$\begin{array}{l}\text { Infections detected } \\
\text { during inpatient } \\
\text { stay }\end{array}$} & a & $\begin{array}{l}\text { Excess length of } \\
\text { stay (days) }\end{array}$ & 2.6 & 2.44 to 2.76 & & & & & \\
\hline & $\mathrm{b}$ & Value per bed day & $£ 444.00$ & & & & & & \\
\hline & C & $\begin{array}{l}\text { No cases }(0.51 \% \\
\text { of } 800 \text { women) }\end{array}$ & 4.1 & 2.3 to 5.8 & & & & & \\
\hline & & Total $=\left(a^{\star} b^{\star} c\right)$ & & & $£ 4722.82$ & & & & $£ 5595.68$ \\
\hline \multirow{4}{*}{$\begin{array}{l}\text { Inpatient detected } \\
\text { SSI subsequently } \\
\text { readmitted }\end{array}$} & a & $\begin{array}{l}\text { Average HRG cost } \\
\text { per spell }\end{array}$ & $£ 1092.20$ & & & & & & \\
\hline & $b$ & Spells per patient & 1 & & & & & & \\
\hline & c & $\begin{array}{l}\text { No cases }(0.05 \% \\
\text { of } 800 \text { women) }\end{array}$ & 0.4 & 0 to 1 & & & & & \\
\hline & & Total $=\left(a^{*} b^{*} c\right)$ & & & $£ 428.14$ & & & & $£ 507.27$ \\
\hline \multirow[t]{4}{*}{$\begin{array}{l}\text { Infections detected } \\
\text { at readmission }\end{array}$} & a & $\begin{array}{l}\text { Average HRG cost } \\
\text { per spell }\end{array}$ & $£ 1387.67$ & & & & & & \\
\hline & $\mathrm{b}$ & Spells per patient & 1.35 & & & & & & \\
\hline & c & $\begin{array}{l}\text { No cases }(0.56 \% \\
\text { of } 800 \text { women) }\end{array}$ & 4.5 & 2.7 to 6.2 & & & & & \\
\hline & & Total $=\left(a^{\star} b^{\star} c\right)$ & & & $£ 8392.63$ & & & & $£ 9943.74$ \\
\hline \multirow{6}{*}{$\begin{array}{l}\text { Infections detected } \\
\text { by community } \\
\text { midwife }\end{array}$} & a & $\begin{array}{l}\text { One extra midwife } \\
\text { visit }\end{array}$ & $£ 63.00$ & & & & & & \\
\hline & $b$ & $\begin{array}{l}\text { One extra visit } \\
\text { to GP }\end{array}$ & $£ 30.00$ & & & & & & \\
\hline & $\mathrm{c}$ & $\begin{array}{l}\text { One course } \\
\text { antibiotics }\end{array}$ & $£ 4.27$ & & & & & & \\
\hline & $d$ & $\begin{array}{l}\text { Microbiology } \\
(£ 13.74)^{*} 43 \%\end{array}$ & $£ 5.91$ & & & & & & \\
\hline & e & $\begin{array}{l}\text { No cases }(5.31 \% \\
\text { of } 800 \text { women) }\end{array}$ & 42.4 & 37.0 to 47.8 & & & & & \\
\hline & & Total $(a+b+c+d)^{\star} e$ & & & & $£ 4383.01$ & & & $£ 5193.07$ \\
\hline \multirow[t]{6}{*}{$\begin{array}{l}\text { Self-reported } \\
\text { infections }\end{array}$} & $\mathrm{a}$ & $\begin{array}{l}\text { One extra visit } \\
\text { to general } \\
\text { practitioner }\end{array}$ & $£ 30.00$ & & & & & & \\
\hline & $\mathrm{b}$ & $\begin{array}{l}\text { One course } \\
\text { antibiotics ( } £ 4.27)\end{array}$ & $£ 4.27$ & & & & & & \\
\hline & $\mathrm{c}$ & $\begin{array}{l}\text { Microbiology } \\
(£ 13.74)^{\star} 30 \%\end{array}$ & $£ 4.12$ & & & & & & \\
\hline & $d$ & $\begin{array}{l}\text { No cases }(3.21 \% \\
\text { of } 800 \text { women) }\end{array}$ & 25.7 & 21.4 to 30.0 & & & & & \\
\hline & & Total $=(a+b+c)^{\star} d$ & & & & $£ 987.14$ & & & $£ 1169.58$ \\
\hline & & Total costs & & & $£ 13544$ & $£ 5370$ & $£ 18914$ & $\begin{array}{l}£ 11521 \text { to } \\
£ 29499\end{array}$ & $£ 22409$ \\
\hline
\end{tabular}

*Inflated to 2019 prices using UK Consumer Price Index-total less food, less energy (Organisation for Economic Co-operation and Development data).

GP, general practitioner; HRG, Healthcare Resource Group; SSI, surgical site infection.

(figure 3). Net savings of $£ 26021$ over the 5-year period were achieved for a strategy of continuous surveillance with a $20 \%$ reduction in infection risk. The simulation for a hospital with a baseline infection risk of $5 \%$ indicated that savings from reducing surgical site infection risk did not offset the costs of surveillance for any of the surveillance strategies.
For a hospital with a baseline surgical site infection risk of $15 \%$, all of the surveillance strategies achieved savings greater than the costs of surveillance over the 5-year period of the simulation when reductions in infection risk of $10 \%, 20 \%$ or $30 \%$ were applied. Breakeven was achieved by the end of year 2 (or sooner) where reductions of $20 \%$ and $30 \%$ at each surveillance period were 
Table 3 Estimated costs for a 3-month surveillance period for surgical site infection following caesarean section for a model hospital conducting 800 caesarean sections per year

\begin{tabular}{|c|c|c|c|c|c|}
\hline Surveillance & & Item & Surveillance & Total & Inflated costs* \\
\hline \multirow[t]{2}{*}{ Surveillance nurse } & a & 0.4 equivalent band 6 surveillance nurse ( $24 \%$ on costs) & $£ 14614$ & & \\
\hline & $\mathrm{b}$ & 1 surveillance quarter & 0.25 & & \\
\hline \multirow[t]{3}{*}{ Administration } & a & Stationery/photocopying/stamps/phone calls & $£ 0.47$ & & \\
\hline & $\mathrm{b}$ & Patients in surveillance quarter & 200 & & \\
\hline & & Total cost & & $£ 3746.54$ & $£ 4438.97$ \\
\hline
\end{tabular}

*Inflated to 2019 prices using UK Consumer Price Index - total less food, less energy (Organisation for Economic Co-operation and Development Data).

applied (figure 4). A saving of $£ 63217$ over the period of simulation was obtained for a $15 \%$ baseline infection risk achieving a $20 \%$ reduction in infections at each surveillance period and employing a continuous surveillance strategy.

When the variable surveillance strategy was modelled (figure 5), this responsive strategy estimated that a net saving of $£ 63234$ would be achieved for a hospital with a $15 \%$ baseline infection risk achieving a $20 \%$ reduction in infections at each surveillance period ( $£ 26696$ savings for $10 \%$ infection risk with $20 \%$ reductions). For hospitals with a $15 \%$ baseline infection risk, breakeven points for the variable surveillance strategy were slightly later compared with the fixed surveillance strategies of one or two surveillance periods a year, due to the continuous surveillance component of the variable strategy. However, for a $10 \%$ baseline infection risk, breakeven was earlier or at the same time for the variable surveillance strategy compared with the original fixed surveillance strategies.

Overall breakeven was reached within the 5-year simulation period with the variable surveillance strategy for scenarios where hospitals had a baseline infection risk of $10 \%$ or $15 \%$ (figures $6-8$ ). The variable surveillance strategy achieved higher (5/9 scenarios) or similar net savings ( $1 / 9$ scenarios) compared with the original surveillance strategies for the equivalent baseline infection risk and reductions in risk of infection. The variable surveillance strategy for hospitals with a $5 \%$ baseline risk of infection was equivalent to the one surveillance period

\section{Key: Surveillance strategy Reductions in SSI risk}

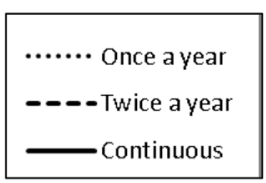

i) SSI risk (\%)

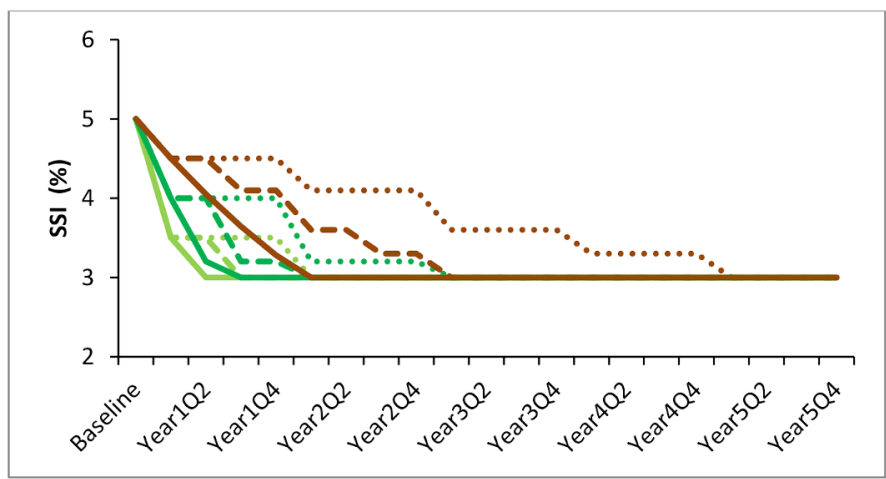

ii) balance of discounted cost versus savings

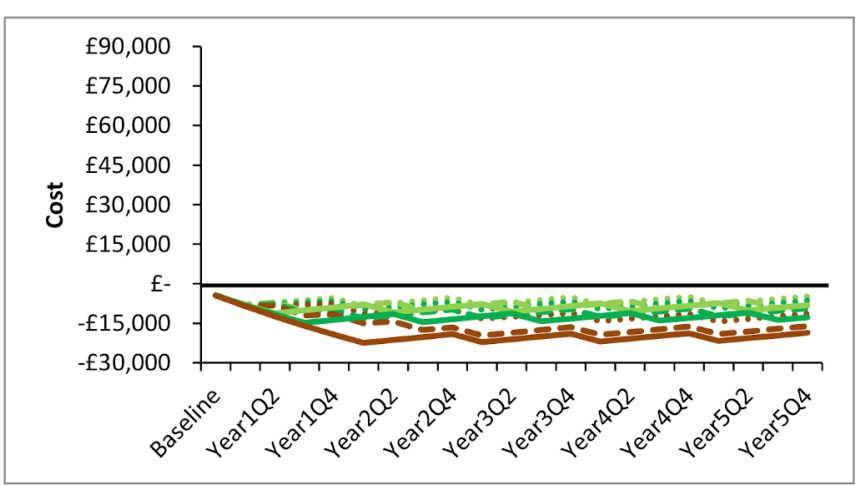

Figure 2 Balance of surveillance cost versus savings from reductions of $10 \%, 20 \%$ and $30 \%$ per surveillance period for surveillance strategies of one quarter a year, two quarters a year and continuous surveillance for starting surgical site infection (SSI) risk of $5 \%$. Model assumes that reductions in infection risk are achieved in conjunction with improvement programmes during surveillance periods and maintained between each surveillance period. No further reductions in risk of infection were included in the model once a postulated minimum SSI risk of $3 \%$ was reached. 
Key: Surveillance strategy

Reductions in SSI risk
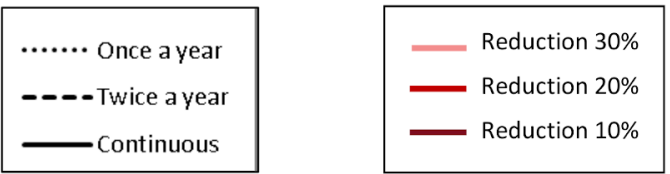

i) SSI risk (\%)

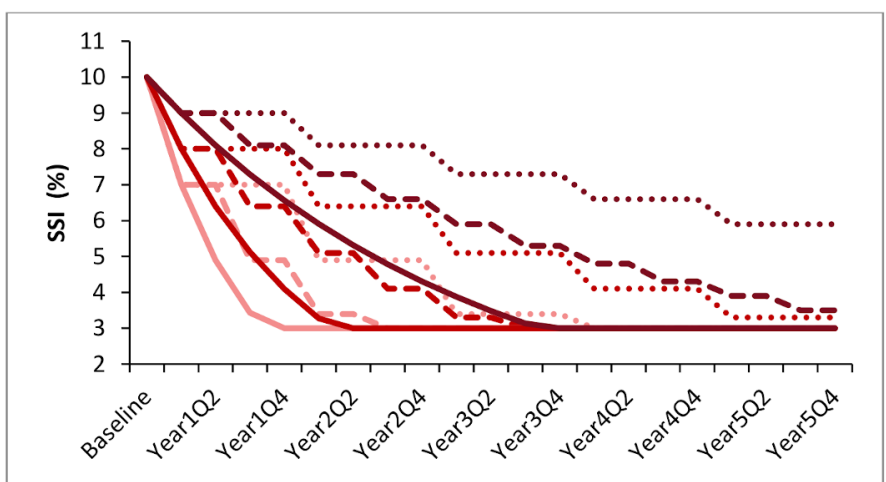

ii) balance of discounted cost versus savings

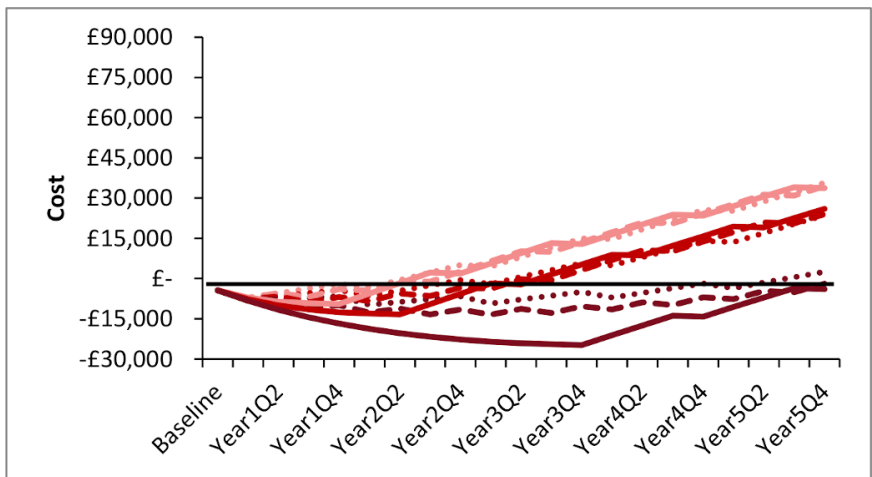

Figure 3 Balance of surveillance cost versus savings from reductions of 10\%,20\% and $30 \%$ per surveillance period for surveillance strategies of one quarter a year, two quarters a year and continuous surveillance for starting surgical site infection (SSI) risk of $10 \%$. Model assumes that reductions in infection risk are achieved in conjunction with improvement programmes during surveillance periods and maintained between each surveillance period. No further reductions in risk of infection were included in the model once a postulated minimum SSI risk of 3\% was reached.

Key: Surveillance strategy Reductions in SSI risk
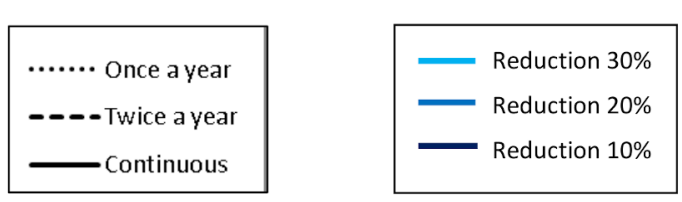

i) SSI risk (\%)

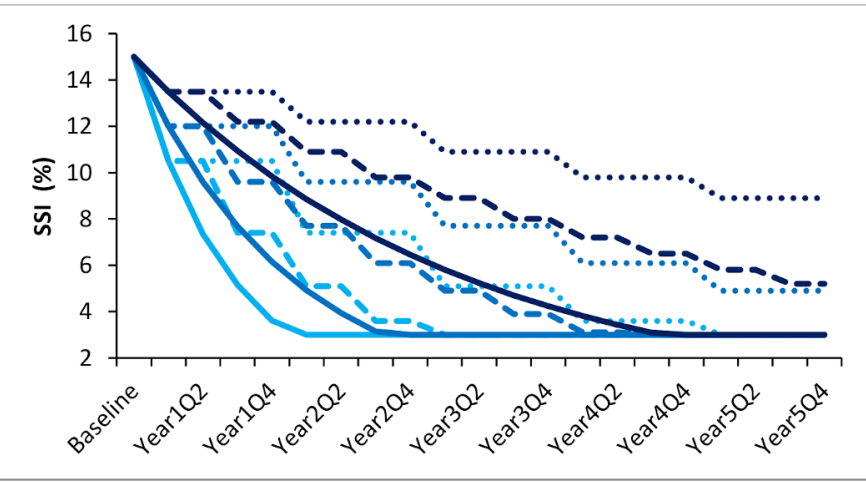

ii) balance of discounted cost versus savings

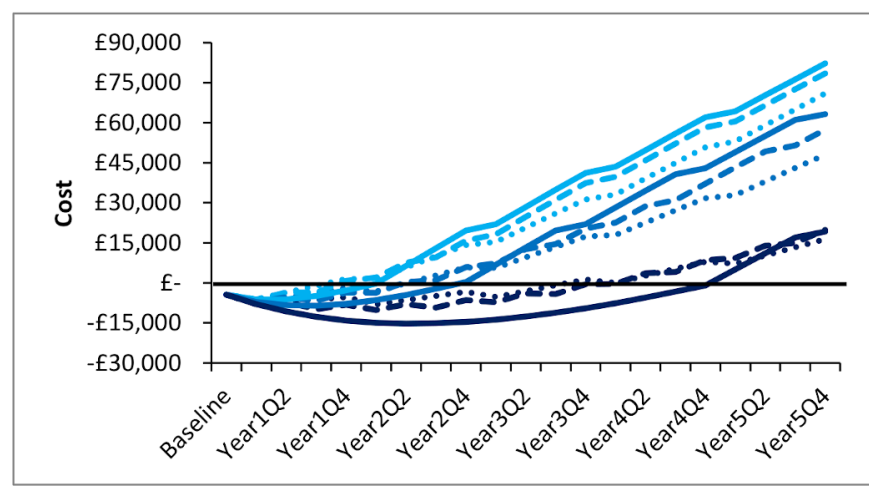

Figure 4 Balance of surveillance cost versus savings from reductions of $10 \%, 20 \%$ and $30 \%$ per surveillance period for surveillance strategies of one quarter a year, two quarters a year and continuous surveillance for starting surgical site infection (SSI) risk of $15 \%$. Model assumes that reductions in infection risk are achieved in conjunction with improvement programmes during surveillance periods and maintained between each surveillance period. No further reductions in risk of infection were included in the model once a postulated minimum SSI risk of 3\% was reached. 


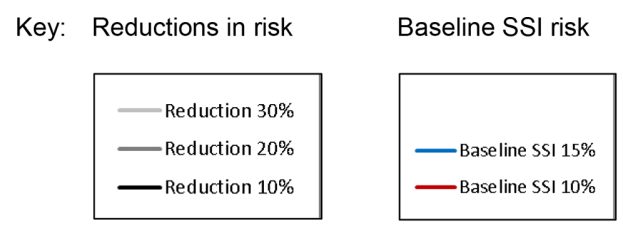

i) SSI risk (\%)

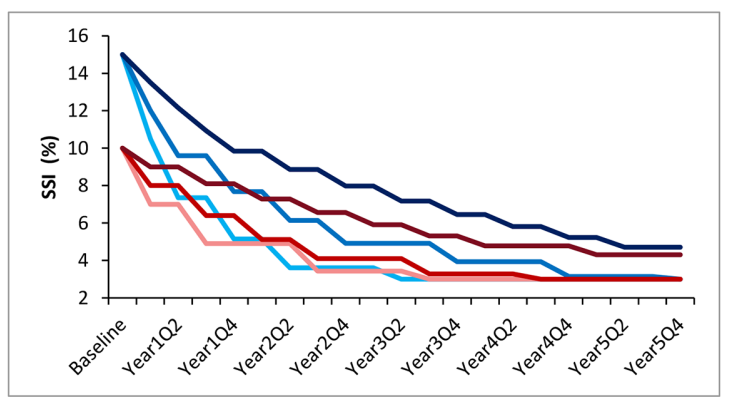

ii) balance of discounted cost versus savings

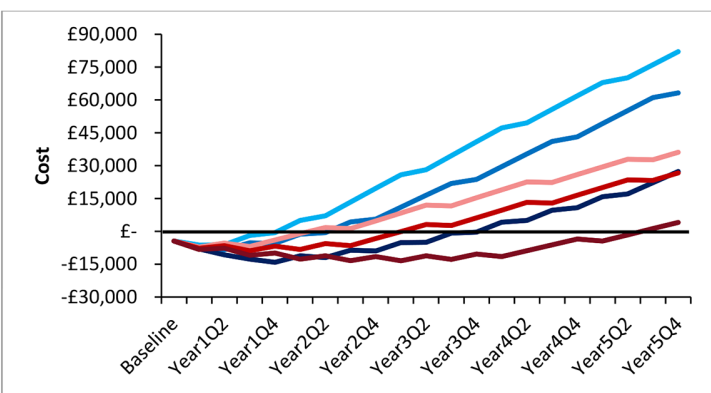

Figure 5 Balance of surveillance cost versus savings from reductions in surgical site infection risk of $10 \%, 20 \%$ and $30 \%$ per surveillance period for baseline surgical site infection (SSI) risk of $10 \%$ or $15 \%$ using a variable surveillance strategy (continuous surveillance when the infection risk is above 10\%, two quarters per year surveillance for infection risk between $5 \%$ and $10 \%$ and one quarter per year surveillance for infection risk below 5\%). Model assumes that reductions in risk of infection are achieved in conjunction with improvement programmes during surveillance periods and maintained between each surveillance period. No further reductions in risk of infection were included once a postulated minimum SSI risk of $3 \%$ was reached.

a year strategy and therefore resulted in equal losses $(3 / 9$ scenarios).

A tool has been designed, based on the costs identified in this study for caesarean section, to predict the time to breakeven for a model hospital employing the variable surveillance strategy and applying self-selecting baseline infection risk, predicted reductions in infection and volume of surgery (online supplementary material).

\section{DISCUSSION}

Our study estimated that surgical site infections in caesarean section cost the NHS in England $£ 5.0$ million a year, equating to $£ 22409$ for a typical hospital conducting 800 caesarean sections per year. Through capture and assessment of the costs of surveillance, our model showed that the benefits of a surveillance strategy can outweigh the costs through reductions in incidence of surgical site infections.

Excess length of stay of patients with infection compared with patients without is frequently used as a proxy for combined inpatient attributable costs. As median length of stay for caesarean section patients was 3 days at the time of the study, and median time to infection was 10 days, the majority of surgical site infections would have occurred after discharge. However, if a woman remains in hospital for reasons other than surgical site infection, there is a chance she might develop a surgical site infection which would otherwise have been detected and managed in the community by her midwife or general practitioner. Therefore, a naive comparison of length of stay between patients with and without a surgical site infection would have produced an overestimate because it would not disentangle the increased chance of detecting an infection for those patients with a prolonged length of stay due to other reasons. ${ }^{19} 20$ A suitable calculation method should account for patient heterogeneity and timing of events to avoid biasing results. A multistate model estimate which accounted for the time-dependent bias was considered; however, this did not naturally incorporate patient heterogeneity. An alternative option was to use a confounder and time matching approach, where suitable control patients should be 'at risk' of acquiring an infection at the time of infection of the corresponding case, which can be satisfied by using the time-to-infection as an additional matching criteria. The advantage of the method used in this study, of matching infected patients with similar uninfected patients with comparable length of postoperative stay prior to infection, is that it produced a more accurate assessment of the excess length of stay directly attributable to the surgical site infection (2.6 days) than the average excess length of stay (median 5 days).

The largest contribution to the overall costs (and the uncertainty) for the model hospital is the excess postdelivery length of stay and the readmission of patients. This equates to approximately $£ 1866$ per infection detected during the inpatient stay or leading to readmission. There are few studies describing costs for surgical site infection following caesarean section and comparisons are hampered by differences in methodology. ${ }^{2122}$ The cost of $£ 1866$ in this study is lower than the median cost of $£ 3716$ calculated by Jenks et al. ${ }^{21}$ There were differences between the two studies in length of stay calculated to be attributable to surgical site infection (4 days vs 2.6 in this study). Our study used a case-matching methodology to account for both time at risk and extraneous factors which would lead to an overestimation of excess length of stay. This, along with our inclusion of data from multiple centres 


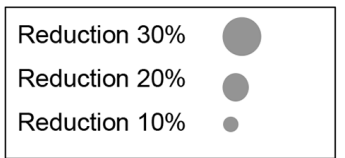

Continuous surveillance

Surveillance twice a year

Surveillance once a year

Variable surveillance strategy

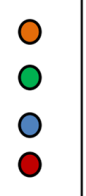

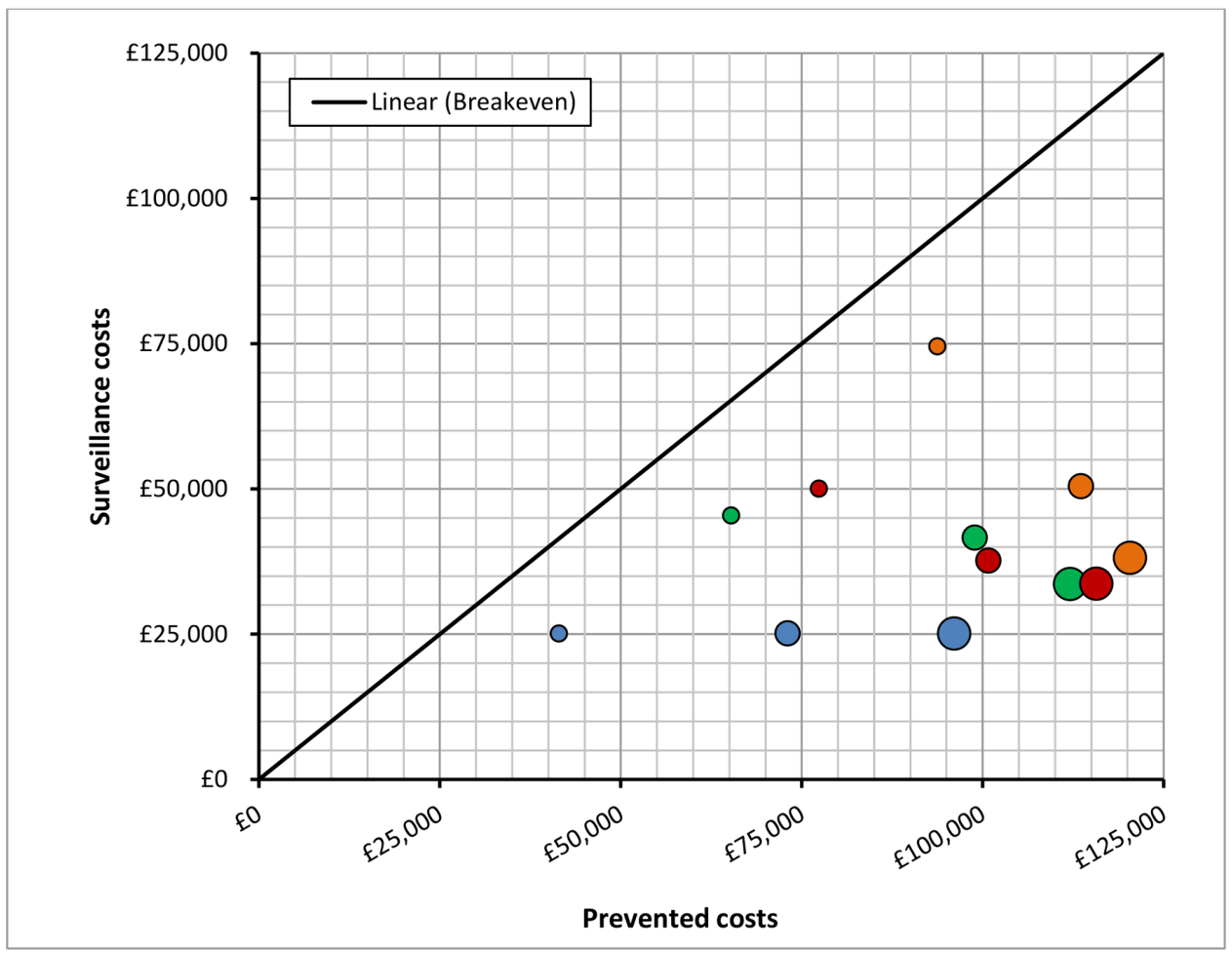

Figure 6 Cumulative discounted prevented costs against costs of surveillance after 5-year surveillance programme-15\% baseline surgical site infection risk.

as opposed to a single site may account for differences in our cost estimates. In our multicentre study, the majority of infections $(52 \%)$ detected at readmission and $24 \%$ of those detected during the initial inpatient stay were the more serious infections (deep incisional or organ/space) which are likely to require more extensive treatment, such as debridement or resuturing, than superficial infections. In contrast, only $11 \%$ of midwife detected surgical site infections were deep or organ/space infections.

Previous studies have focused primarily on hospital costs. $^{21-23}$ By including an estimate of the costs in the community in this analysis, a more representative estimate of overall economic burden to the health service was achieved. More than $28 \%$ of the economic burden arose in the community where the majority of these infections are managed. A study of breast surgery in England which included postdischarge follow-up also found a similar proportion of costs incurred in the community $(31 \%) .{ }^{24}$ In contrast, a study conducted in Scotland in 2001, using actual rather than estimated bed days and general practitioner visits, identified $11 \%$ of treatment costs resulting from surgical site infection occurred in the community. ${ }^{25}$ However, that study included non-obstetric surgical procedures (which would not have incurred midwife costs).

\section{Limitations}

As well as applying the National Schedule Reference Costs to provide the average cost of hospital stay, rather than actual observed expenditure, various assumptions have been made in this study including the number of extra midwife and general practitioner appointments resulting from infection. However, there are likely to be additional costs to those outlined. For example, some of the patients readmitted for more serious infections may also require a hospital outpatient follow-up appointment or further general practitioner visits. Also, additional outpatient appointments and more than one course of antibiotics may be needed to treat infections identified by midwives and general practitioners. Given that our analysis was based on healthcare utilisation, excluding additional costs (direct and indirect) incurred by the affected women or their carers, the true costs associated with these infections are likely to be higher than our estimates. The intangible costs resulting from the pain and suffering of the women were not assessed although wound infections 

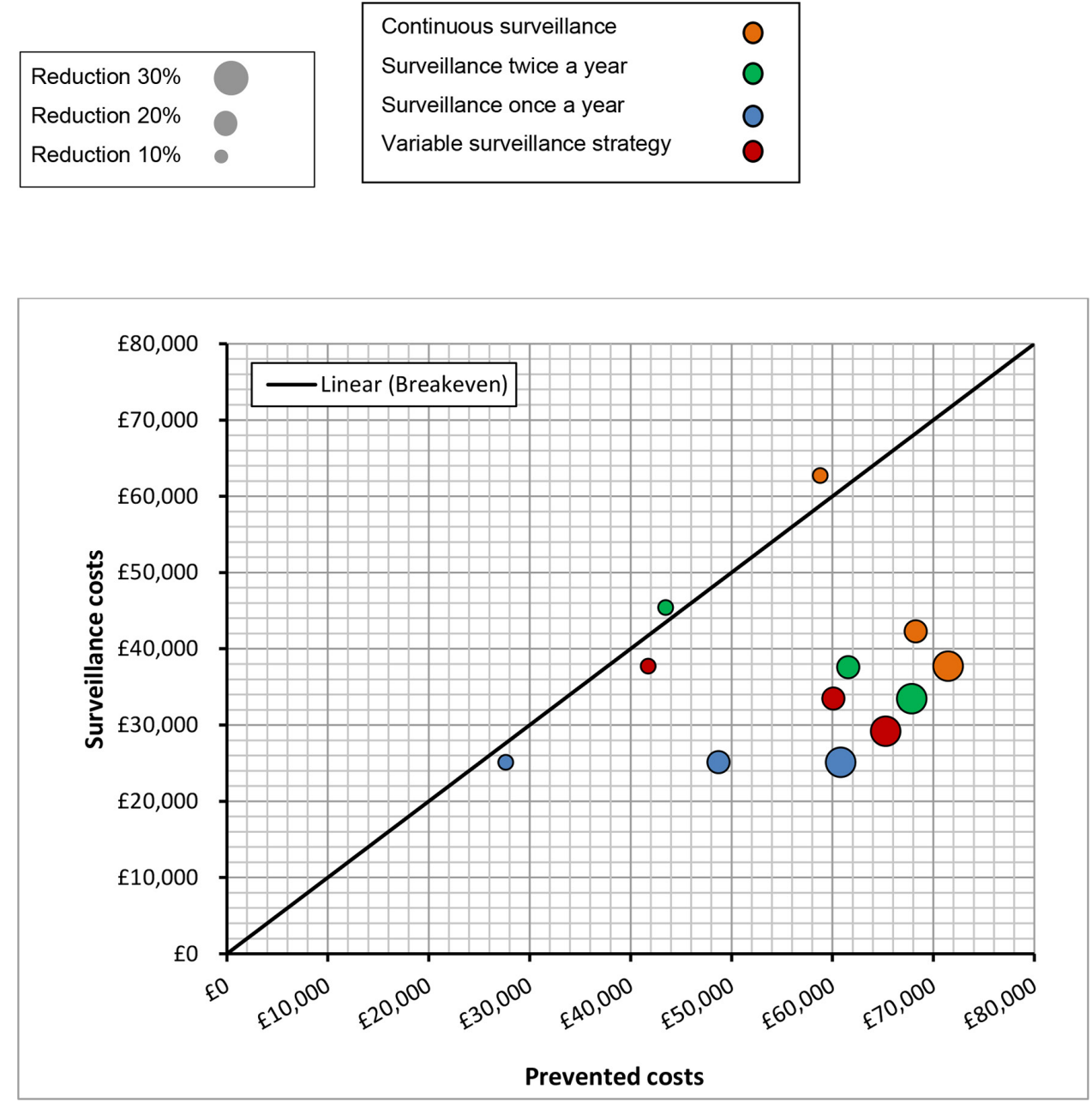

Figure 7 Cumulative discounted prevented costs against costs of surveillance after 5 -year surveillance programme-10\% baseline surgical site infection risk.

and endometritis following caesarean section have been reported to increase anxiety and delay physical recovery for these women, with consequent impact on their ability to care for their new born. ${ }^{26}$ While the majority of women will be on maternity leave, family members or other carers may require time off work to look after the patient or to provide childcare for the newborn or other children. An extensive prospective study would be required to gain more comprehensive information on the detailed costs associated with surgical site infection following caesarean section.

Although the reductions in surgical site infection risk in the model are supported by the data from the cohort study (figure 1), the surveillance was only repeated once and two of hospitals did not achieve reductions. Therefore, there is no guarantee that such reductions would be sustained over time. Additionally, decreases in risk of infection between surveillance cycles will in reality vary over time within a given hospital and a constant rate of reduction in infections is unlikely to offer a true reflection of this pattern. This study has applied an average reduction rate in risk of infection but, as further information becomes available on patterns of reduction, the model can be adapted.

There may be additional costs associated with setting up and running surveillance such as training community midwives and feedback meetings with surgeons but these costs can be minimised by incorporating time into existing infection prevention, maternity or surgical meetings. While it could be argued that surveillance drives adherence to infection control practices that should be in place already, where such measures are not in place additional infection prevention and control measures may incur costs. However, changes to many infection prevention measures may be cost neutral and additional costs for specific interventions can be considered once identified.

The community costs estimated in this study are not incurred by the hospital and, as hospitals would not realise any savings from community care by reducing these infections, this could be a disincentive to hospitals carrying out surveillance and setting up new infection control measures. 

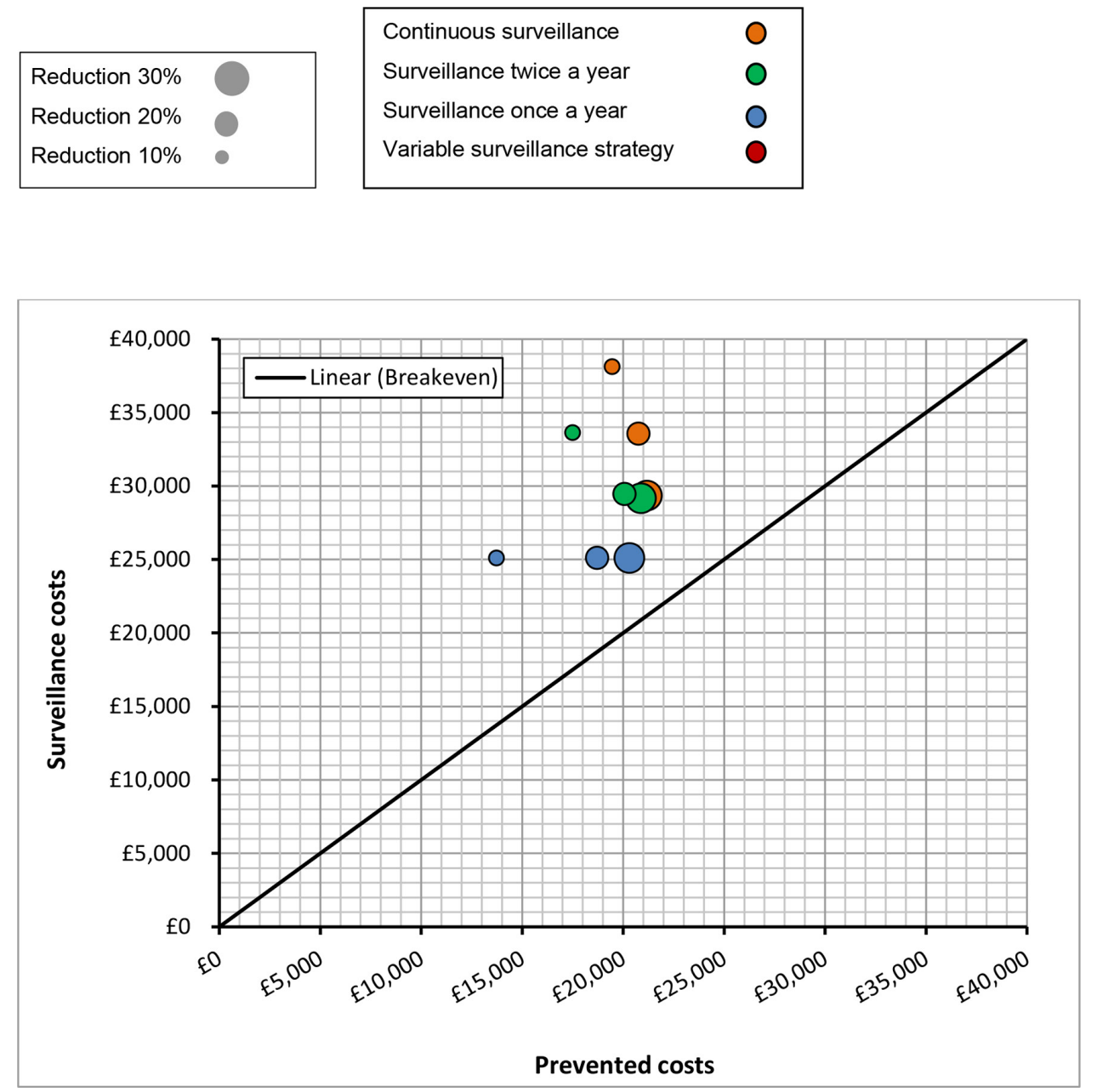

Figure 8 Cumulative discounted prevented costs against costs of surveillance after 5-year surveillance programme-5\% baseline surgical site infection (SSI) risk. *Variable surveillance strategy is equivalent to once-a-year surveillance where SSI risk is $<5 \%$.

\section{Implications for surveillance}

Surgical site infection surveillance schemes which include feedback of results to surgeons have been found to reduce risk of infections ${ }^{27} 28$ and individual hospitals have successfully reduced infection risk by applying measures to improve practice. ${ }^{1529}$ The National Institute for Health and Care Excellence ${ }^{30}$ and $\mathrm{WHO}^{31}$ guidelines for preventing surgical site infection recommend various approaches to reduce infection risk including the timing of antimicrobial prophylaxis, avoiding shaving, antiseptic skin preparation, maintaining patient homeostasis, covering wounds with an interactive dressing and prevention of hypothermia. ${ }^{32}$ While health services may aim to achieve a zero risk of infection, it is likely that there is an irreducible minimum risk for some surgical categories beyond which there will be limited opportunities for further reductions. Such a possibility was built into the model. In some hospitals, high infection risks may be due to underlying systemic problems and reductions in infection risk may take longer in these more complex situations. Local needs of individual hospitals will need to be assessed.
This study estimated the cost of surveillance for one 3-month period as $£ 4439$ for a model hospital conducting 800 caesarean sections a year. A continuous surveillance programme would provide a more rapid decrease in infection risk, when accompanied by improvements in care, than surveillance strategies of one or two quarters a year. However, although the continuous surveillance model achieved savings for hospitals with higher baseline infection risk, it did not achieve the greatest balance of saving against costs of surveillance over the 5-year simulation period for scenarios with a $10 \%$ reduction in infections between surveillance periods. The variable surveillance model achieved similar or greater savings or smaller losses for all baseline infection risks. Extrapolating from these findings, hospitals could consider a variable surveillance strategy of continuous surveillance for hospitals with high risk of infection (greater than 10\%) to rapidly reduce infections and patient harm as quickly as possible. Surveillance for caesarean section could then be reduced to two quarters a year once the infection risk has decreased to $10 \%$ and to one quarter per year when the infection risk declines to $5 \%$ to maximise savings. In terms of cost 
saving, this approach is supported by the model estimates for such a variable surveillance programme identified by this study. A minimum surveillance strategy of one quarter a year would then be useful to reinforce infection control measures and provide continued vigilance to sustain low levels of infection. However, the strategy outlined in this model may not be applicable to other surgical categories, particularly those with a low infection risk.

Although a variable surveillance strategy can be less costly and can be tailored to the baseline infection risk of a hospital, conducting continuous surveillance has advantages. These include having well-established surveillance systems with methodology embedded in practice, and providing a more precise estimate of infection risk where surgical volumes are low. Additional savings to those presented in this study could be achieved through reducing surveillance costs, for example, through use of patient-facing digital technologies, currently under development, to collect patient-reported infections. ${ }^{33}$

\section{Patient outcomes}

The number of caesarean sections performed each year in England has been rising since the $1980 \mathrm{~s}^{2}$ accompanied by an increase in the proportion of women of childbearing age who are obese. ${ }^{34}$ High BMI has been identified as a key risk factor for surgical site infection following caesarean section. ${ }^{6}$ This means that with rising obesity surgical site infections are likely to become an increasing burden for the health service. Reducing the risk of infections following caesarean section is an important health issue for these women who are otherwise generally young and healthy.

The multicentre cohort study identified 1 in 10 women with surgical site infection following caesarean section. ${ }^{6}$ There is currently no national surveillance for surgical site infection following caesarean section in England, although it is mandatory in Scotland, Wales and Northern Ireland and there is considerable support from hospitals to introduce this in England. ${ }^{35} 36$

Although costs incurred by surgical site infection following caesarean section are lower than those associated with infections following orthopaedic and other surgical categories ${ }^{37-40}$ infections post caesarean can still lead to serious outcomes, ${ }^{7142}$ and may give rise to high cost clinical negligence claims. ${ }^{43}$ However, the decision to attempt to reduce risk of surgical site infection is not solely about cost saving. Hospitals have a duty to avoid harm to the patient, reduce antibiotic consumption and improve patient experience.

\section{CONCLUSION}

Surgical site infection following caesarean section causes pain and anxiety to new mothers and incurs a financial burden to the healthcare system in both community and hospital healthcare settings. Integrating caesarean section surveillance into the national surveillance programme would provide hospitals with the infrastructure (and national benchmark) for reducing infection by feeding back data and thereby empowering staff to take action to improve patient care and potentially reduce costs.

Acknowledgements The authors would like to thank Julie Robotham (PHE) for her expert guidance as well as the hospitals who contributed information on the cost of microbiological screening and surveillance resources. They would also like to thank NHS Digital for permission to reuse Hospital Episode Statistics, Copyright NHS Digital @ 2010. All rights reserved.

Contributors CW and TL designed the study. CW, JC, PH and ES sourced cost data. CW analysed the cost data, constructed the initial cost model and wrote the paper. NG conducted the paired matching analysis and AJVH calculated uncertainty and advised on the model construction and JW designed the multicentre study. All authors critically reviewed and contributed to the final draft of the paper. TL is the guarantor.

Funding The authors have not declared a specific grant for this research from any funding agency in the public, commercial or not-for-profit sectors.

Competing interests None declared.

Patient consent for publication Not required.

Ethics approval Public Health England has approval from the Confidentiality Advisory Group of the Health Research Authority for the processing of confidential patient information in support of the PHE Surgical Site Infection Surveillance Service through its devolved responsibility under Regulation 3 of the Health Service (Control of Patient Information) Regulations of 2002 (made under the powers given to the Secretary of State in Section 251, NHS Act 2006). Regulation 3: Surveillance and control of public health hazards explicitly including infectious disease.

Provenance and peer review Not commissioned; externally peer reviewed.

Data availability statement No data are available.

Open access This is an open access article distributed in accordance with the Creative Commons Attribution Non Commercial (CC BY-NC 4.0) license, which permits others to distribute, remix, adapt, build upon this work non-commercially, and license their derivative works on different terms, provided the original work is properly cited, appropriate credit is given, any changes made indicated, and the use is non-commercial. See: http://creativecommons.org/licenses/by-nc/4.0/.

ORCID iD

Catherine Wloch http://orcid.org/0000-0002-9294-3588

\section{REFERENCES}

1 OECD. Health at a Glance 2017: OECD Indicators. OECD, 2018. Available: https://www.oecd-ilibrary.org/social-issues-migrationhealth/health-at-a-glance-2017_health_glance-2017-en [Accessed 14 Sep 2018].

2 NHS Digital. NHS Maternity Statistics, England 2018-19. NHS Digital, 2019. Available: https://digital.nhs.uk/data-and-information/ publications/statistical/nhs-maternity-statistics/2018-19 [Accessed 29 Apr 2020].

3 Ward VP, Charlett A, Fagan J, et al. Enhanced surgical site infection surveillance following caesarean section: experience of a multicentre collaborative post-discharge system. J Hosp Infect 2008;70:166-73.

4 Johnson A, Young D, Reilly J. Caesarean section surgical site infection surveillance. J Hosp Infect 2006;64:30-5.

5 Caesarean-section surgical site infection surveillance. Annual report: all Wales. Public Health Wales, 2017. Available: http://www2.nphs. wales.nhs.uk:8080/WHAIPDocs.nsf/3dc04669c9e1eaa880257062 003b246b/5b9c050161b447408025821100359f6f/\$FILE/2016\% 20All\%20Wales\%20SSI\%20Annual\%20Report\%20-\%20V1.pdf [Accessed 6 Dec 2018].

6 Wloch C, Wilson J, Lamagni T, et al. Risk factors for surgical site infection following caesarean section in England: results from a multicentre cohort study. BJOG 2012;119:1324-33.

7 Cantwell R, Clutton-Brock T, Cooper G, et al. Saving mothers' lives: reviewing maternal deaths to make motherhood safer: 2006-2008. The eighth report of the Confidential enquiries into maternal deaths in the United Kingdom. BJOG 2011;118 Suppl 1:1-203.

8 Haley RW, Culver DH, White JW, et al. The efficacy of infection surveillance and control programs in preventing nosocomial infections in US hospitals. Am J Epidemiol 1985;121:182-205. 
9 Gastmeier P, Geffers C, Brandt C, et al. Effectiveness of a nationwide nosocomial infection surveillance system for reducing nosocomial infections. J Hosp Infect 2006;64:16-22.

10 Abbas M, de Kraker MEA, Aghayev E, et al. Impact of participation in a surgical site infection surveillance network: results from a large international cohort study. J Hosp Infect 2019;102:267-76.

11 Wilson J, Wloch C, Saei A, et al. Inter-Hospital comparison of rates of surgical site infection following caesarean section delivery: evaluation of a multicentre surveillance study. J Hosp Infect 2013;84:44-51.

12 Department of Health. 2010-11 reference costs publication, 2018. Department of Health. Available: https://www.gov.uk/government/ publications/2010-11-reference-costs-publication [Accessed 25 July 2018].

13 Business Services Authority. NHS Drugs Tariff. Business Services Authority, 2018. Available: https://www.nhsbsa.nhs.uk/pharmaciesgp-practices-and-appliance-contractors/drug-tariff [Accessed $25 \mathrm{Jul}$ 2018].

14 National Institute for Health and Care Excellence. Guide to methods of technology appraisal, 2013. Available: https://www.nice.org.uk/ process/pmg9/chapter/foreword [Accessed 7 Jun 2017].

15 Dyrkorn OA, Kristoffersen M, Walberg M. Reducing post-caesarean surgical wound infection rate: an improvement project in a Norwegian maternity clinic. BMJ Qual Saf 2012;21:206-10.

16 Corcoran S, Jackson V, Coulter-Smith S, et al. Surgical site infection after cesarean section: implementing 3 changes to improve the quality of patient care. Am J Infect Control 2013;41:1258-63.

17 European Centre for Disease Prevention and Control. Surveillance of surgical site infections in Europe, 2010-2011. European Centre for Disease Prevention and Control, 2013. Available: https://www.ecdc. europa.eu/en/publications-data/surveillance-surgical-site-infectionseurope-2010-2011 [Accessed 12 Mar 2020].

18 OECD. Inflation (CPI)(Indicator). OECD, 2020. Available: https://data. oecd.org/price/inflation-cpi.htm [Accessed 29 Apr 2019].

19 Kappstein I, Schulgen G, Beyer U, et al. Prolongation of hospital stay and extra costs due to ventilator-associated pneumonia in an intensive care unit. Eur J Clin Microbiol Infect Dis 1992;11:504-8.

20 De Angelis G, Murthy A, Beyersmann J, et al. Estimating the impact of healthcare-associated infections on length of stay and costs. Clin Microbiol Infect 2010;16:1729-35.

21 Jenks PJ, Laurent M, McQuarry S, et al. Clinical and economic burden of surgical site infection (SSI) and predicted financial consequences of elimination of SSI from an English Hospital. J Hosp Infect 2014;86:24-33.

22 Olsen MA, Butler AM, Willers DM, et al. Attributable costs of surgical site infection and endometritis after low transverse cesarean delivery. Infect Control Hosp Epidemiol 2010;31:276-82.

23 Mugford M, Kingston J, Chalmers I. Reducing the incidence of infection after caesarean section: implications of prophylaxis with antibiotics for hospital resources. BMJ 1989;299:1003-6.

24 Tanner J, Khan D, Ball J, et al. The rate, risk factors and cost of surgical site infections in primary breast surgery. $J$ Infect Prev 2011;12:204-9.

25 Reilly J, Twaddle S, Mclntosh J, et al. An economic analysis of surgical wound infection. J Hosp Infect 2001;49:245-9.

26 Kealy MA, Small RE, Liamputtong P. Recovery after caesarean birth: a qualitative study of women's accounts in Victoria, Australia. BMC Pregnancy Childbirth 2010;10:47.

27 Bärwolff S, Sohr D, Geffers C, et al. Reduction of surgical site infections after caesarean delivery using surveillance. $J$ Hosp Infect 2006;64:156-61.
28 Astagneau P, L'Hériteau F, Daniel F, et al. Reducing surgical site infection incidence through a network: results from the French ISORAISIN surveillance system. $J$ Hosp Infect 2009;72:127-34.

29 Gregson $\mathrm{H}$. Reducing surgical site infection following caesarean section. Nurs Stand 2011;25:35-40.

30 National Collaborating Centre for Women's and Children's Health. Surgical site infection - prevention and treatment of surgical site infection. Clinical Guideline 74. NICE, 2008. Available: http://www. nice.org.uk/guidance/CG74 [Accessed 23 Oct 2015].

31 World Health Organisation. Global guidelines for the prevention of surgical site infection, 2016. Available: http://www.who.int/gpsc/ssiguidelines/en/ [Accessed 7 Jun 2017].

32 National Institute for Health and Care Excellence. Hypothermia: prevention and management in adults having surgery, CG65, 2016. Available: https://www.nice.org.uk/guidance/cg65 [Accessed 7 Jun 2017].

33 Public Health England. Surveillance of surgical site infections in NHS hospitals in England 2015/16. public health England, 2016. Available: https://www.gov.uk/government/publications/surgicalsite-infections-ssi-surveillance-nhs-hospitals-in-england [Accessed 12 Mar 2020].

34 Health Survey for England, 2016. NHS Digital, 2017. Available: https://digital.nhs.uk/data-and-information/publications/statistical/ health-survey-for-england/health-survey-for-england-2016 [Accessed 12 Mar 2020].

35 Scotland HP. Pan Celtic collaborative surgical site infection surveillance report: surveillance of surgical site infection for caesarean section procedures performed in Northern Ireland, Scotland and Wales in 2008: health protection Scotland, 2014. Available: https://www.hps.scot.nhs.uk/web-resources-container/ pan-celtic-collaborative-surgical-site-infection-surveillance-reportsurveillance-of-surgical-site-infection-for-caesarean-sectionprocedures-performed-in-northern-ireland-scotland-and-wales-in2008 [Accessed 12 Mar 2020].

36 Godbole G, Wloch C, Harrington P, et al. Future priorities of acute hospitals for surgical site infection surveillance in England. $J$ Hosp Infect 2018;100:371-7.

37 Coello R, Charlett A, Wilson J, et al. Adverse impact of surgical site infections in English hospitals. J Hosp Infect 2005;60:93-103.

38 Merollini KMD, Crawford RW, Whitehouse SL, et al. Surgical site infection prevention following total hip arthroplasty in Australia: a cost-effectiveness analysis. Am J Infect Control 2013;41:803-9.

39 Badia JM, Casey AL, Petrosillo N, et al. Impact of surgical site infection on healthcare costs and patient outcomes: a systematic review in six European countries. J Hosp Infect 2017:96:1-15.

40 Vanhegan IS, Malik AK, Jayakumar P, et al. A financial analysis of revision hip arthroplasty: the economic burden in relation to the National tariff. J Bone Joint Surg Br 2012;94:619-23.

41 Schumacher $\mathrm{H}$, Tehrani $\mathrm{H}$, Irwin MS, et al. Abdominoplasty as an adjunct to the management of peri-Caesarian section necrotising fasciitis. J Plast Reconstr Aesthet Surg 2008;61:807-10.

42 Melendez J, Claxton A, Erskine K. Mrsa bacteraemia after caesarean section wound infection: when screening is missed and things go wrong. Arch Gynecol Obstet 2012;285:663-5.

43 National Audit Office. Managing the costs of clinical negligence in trusts. National Audit Office, 2017. Available: https://www.nao. org.uk/report/managing-the-costs-of-clinical-negligence-in-trusts/ [Accessed 11 Jan 2018]. 